\title{
Research on the Visual Design of Data Charts Based on the COVID-19 Epidemic
}

\author{
Qiu Feng ${ }^{1}$, Ren Fuchen ${ }^{1}$ \\ ${ }^{1}$ Wuhan Institute of Technology, School of Art and Design, Wuhan 430205
}

\begin{abstract}
Purpose The sudden outbreak of the novel coronavirus has caused varying degrees of damage to China and the world. In today's era of information explosion, data and information are the driving force for decision-making. The improvement of medical treatment and public health systems is the most fundamental, but what a citizen needs is an intuitive and clear "seeing" the development of the epidemic. The correct trend, an accurate view and understanding of the epidemic requires us to use visual design methods to present it to the public, which is helpful to establish a correct understanding of the psychological construction of antiepidemic at the social level.
\end{abstract}

\section{Introduction}

Lovecraft once wrote this sentence in "The Supernatural Terror in Literature": The oldest and strongest emotion of human beings is fear, and the oldest and strongest fear comes from the unknown. In the face of the sudden outbreak of the new coronavirus epidemic spreading to the world, almost everyone's life and destiny have been affected to varying degrees. In addition to the super infectiousness of the epidemic, the new coronavirus also appeared in a new way, such as "undocumented infections", "individuals with ultra-long incubation period infections", and "nucleic acid reexaminations after being cured and discharged." "Positive patients" and so on have brand-new features that infectious bacteria and viruses did not have in the past. The emergence of new bacteria and viruses will face new challenges, which will not only increase the cost and difficulty of their prevention and treatment, but also bring more to the general public. The fear is caused by the unknown. With the continuous development of the epidemic, relevant government departments collect daily domestic and foreign epidemic data visualization information from major media or institutions to grasp the development trend of the epidemic, and continuously optimize the content and methods of visual presentation. We should collect, analyze and summarize the visual design plan of the epidemic, and discover the visual characteristics and deficiencies of the epidemic data, so as to help improve and optimize the visual design of the epidemic data in the future, and use more accurate and intuitive methods for relevant departments. In the future, it will provide scientific reference for disease surveillance, medical resource allocation, and personnel flow management, so that the public will not blindly follow or listen to rumors in order to cooperate with relevant government departments to provide assistance.

\section{2 data visualization}

\subsection{The concept of data visualization}

Data visualization originated from computer graphics in the 1960s. People use computers to create graphs and charts, visualize the extracted data, and present various attributes and variables of the data. With the development of computer hardware, people create more complex and larger digital models, and develop data acquisition equipment and data storage equipment. Similarly, more advanced computer graphics techniques and methods are needed to create these large-scale data sets. With the expansion of the data visualization platform, the increase in application fields, the continuous changes in the form of expression, and the addition of real-time dynamic effects, user interaction, etc., the boundaries of data visualization, like all emerging concepts, continue to expand.

The pie charts, histograms, scatter charts, and histograms that we are familiar with are the most primitive statistical charts. They are the most basic and common applications of data visualization. As a statistical tool, it is used to create a shortcut to quickly understand the data set and become a convincing means of communication. Convey the basic information that exists in the data. So we can see statistical graphics in a large number of PPT, reports, programs, and news.

But the most primitive statistical charts can only present basic information, discover the structure in the data, and visualize quantitative data results. In the face of complex or large-scale heterogeneous data sets, such as business analysis, financial statements, population status distribution, media effect feedback, user behavior data, 
etc., the situation of data visualization will be much more complicated.

Generally, a series of complex data processing, including data collection, analysis, intelligence, management, and mining, is designed by the designer to design a form of expression, whether it is threedimensional, two-dimensional, dynamic, real-time, or allows interaction. Then the engineer creates the corresponding visualization algorithm and technical implementation means. And the technical implementation means include modeling methods, processing large-scale data architecture, interactive technology, zoom-in and zoom-out methods, etc.

\subsection{Design principles of data visualization}

\subsubsection{Usefulness}

One of the design principles of data visualization is usefulness, which means that the products and product functions designed by designers should be able to meet the basic original needs of users. The needs of users come from many aspects, such as desires, moods, beliefs, etc. In the epidemic data visualization works, most of the users' needs are derived from social cognitive orientation, that is, to understand the world correctly and see the development trend of the epidemic. Wait. In the early stages of the outbreak, most of the epidemic information obtained by the masses came from intermittent and fragmented news reports. The work of epidemic data visualization should be comprehensively sorted and classified from multiple dimensions of data, mainly based on various nouns, such as the number of newly diagnosed cases, the cumulative number of confirmed cases, the cumulative number of cured cases, the cumulative number of deaths, etc., and the sub-sections are clearly expressed Data to meet the original needs of users.

\subsubsection{Ease of use}

The design principles of data visualization usability include scientificity, memorability, bottom fault, fault tolerance and efficiency. It must be easy to understand. Data visualization tools usually have generated charts and tables full of text. The awakening data visualization design is to make the visual effect better, and the design results must be very easy to understand, so that you don't understand. Data analysis technology and IT technology can be understood by people who do not know anything about sales and business departments. In many cases, data visualization results are used for reporting. These reports may be internal or external. It is also important to make the data visualization report easy to understand. For the visual design of the epidemic, what we need to do is to accurately grasp the psychological needs of different types of users, conform to the user's operating habits, and make it easier for users to understand the different levels of information brought about by different operations.

\subsubsection{Subjective satisfaction}

Subjective satisfaction refers to the user's subjective experience of using the product. There are many factors that affect the user's subjective experience, which can be roughly divided into three parts: information architecture, interactive experience, and visual design. The level of the information structure affects the user's operation logic. It is necessary to rationally arrange the information level, clearly display the logical relationship between the various levels of data, and distinguish between primary and secondary. In the interactive experience stage, users change from passively receiving data to actively controlling data and exploring information. The principle of aesthetics is an important criterion that cannot be ignored in the design of information transmission. All design works will be displayed in visual form. The visual communication theory is used to present the epidemic information in the process of disseminating information, which will make the warning information more eyecatching, allowing users to grasp the data information more clearly and intuitively, and improve the public's awareness of prevention through different color matching, graphics matching, and material matching. Reduce the people's fear and anxiety, so that the people can see the direction of the epidemic more intuitively.

When evaluating and comparing two infographics of data content, task-based evaluation research can be used to objectively measure and compare whether their functions are effective, as well as the appropriateness, attractiveness, aesthetics and visual effects of visual expressions. Epidemic visualization works need to convey objective information more rigorously and accurately, so the trade-off between function and form is particularly important.

\section{Early classic cases}

As early as the early 19th century, William Playfair (WIlliam Playfair) used a stream graph similar to what people have reduced to today, listing layers representing different categories of information on the timeline. This form is called a stacked graph. (Stackedgraph).

In the early days, Playfair's import and export map for the United Kingdom (Figure 1) can be intuitively opened to the extent that the United Kingdom is intended to gain profits in foreign trade. In the picture, one layer is for British exports, and the other is for British imports. When the UK's import curve is much higher than the import curve, this area of the difference between imports and exports is marked as a "balance in favor of the UK." The creation of this kind of graphics has its advantages. The advantage is that we can obtain knowledge directly from the graph, and decision makers can more quickly grasp the changes in market conditions across multiple data sets. Its disadvantage is that it is still difficult for decision makers to understand, because some methods of stacking layers will make people's visual focus focus on the height difference between the layer and the layer, which is difficult when the width of multiple layers is close. Recognition; each layer must be transparent, otherwise 
some layers may be completely hidden by the previous layer. Its most fundamental feature is that the overall width and length ratio of the river will strongly affect the steepness of the curve in the graph. It may be because of the above reasons that flow graphs have not been widely used in the past 200 years.

\subsection{Nightingale Rose Chart}

The famous British nursing pioneer Florence Nightingale (Florence Nightingale), she not only has high attainments in nursing, but also has her own unique insights in the field of visual and statistical graphics.

From 1854 to 1856 , the Crimean War broke out between the British and French coalition forces and Tsarist Russia. Nightingale served as a British army nurse. During the war, she used the form of a pie chart to count and present the soldiers' casualties. Because it looked like a rose, it was also called the "Nightingale Rose Chart" (also known as the "Celosia Chart", Figure 2). The rose diagram drawn by Nightingale is based on the center of the circle, and each fan shape extends from the center of the circle. The size of the fan shape represents the size of the data. In 1807 Playfair invented the pie chart. But this picture is obviously different from the pie chart drawn by Playfair. The length of each sector is not exactly the same. Different colors are used in each sector, and different colors represent different types. In Figure 2, the left image shows the number of deaths and the cause of death in the second round of British soldiers. There are a total of 12 sectors in the picture, representing 12 months of data, from April 1855 to March 1856. Each fan uses a different color, and the different colors represent the cause of the soldier's death. They are composed of red, black, and blue. The red area closest to the center of the circle represents the number of soldiers who died on the battlefield, the middle black area represents the number of soldiers who died from other causes, and the outermost blue area represents the number of soldiers who died of injuries and did not receive good medical treatment; and the right one The rose map shows the number of deaths and causes of death in the first round of the British army. It lasted for 12 months from April 1854 to March 1855. The color of each sector in the picture represents the same meaning as the picture on the left. The largest blue area in the picture on the right is the outbreak of the Kostai War in January 1855, and the blue area represents not the number of people who died in the war, but the number of soldiers who were injured but were not effectively treated. Nightingale replaced the lengthy text report form with this concise and clear chart form, and reported the real "murderer" of the war to the military's high level through this heterogeneous explanation. After the petition, the death toll of soldiers dropped sharply, and half a year later, the death toll of the wounded and sick dropped from $42 \%$ to $2 \%$. The victory of this British war cannot be said to be won by drawing a rose diagram alone, but he saved many soldiers' lives in this way. This two-point presentation of data can make readers understand and impress the current war situation at a glance, and many cases later followed this form of expression.

Exports and Imports to and DENMARK \& NORWAY from 1700 to 1780.

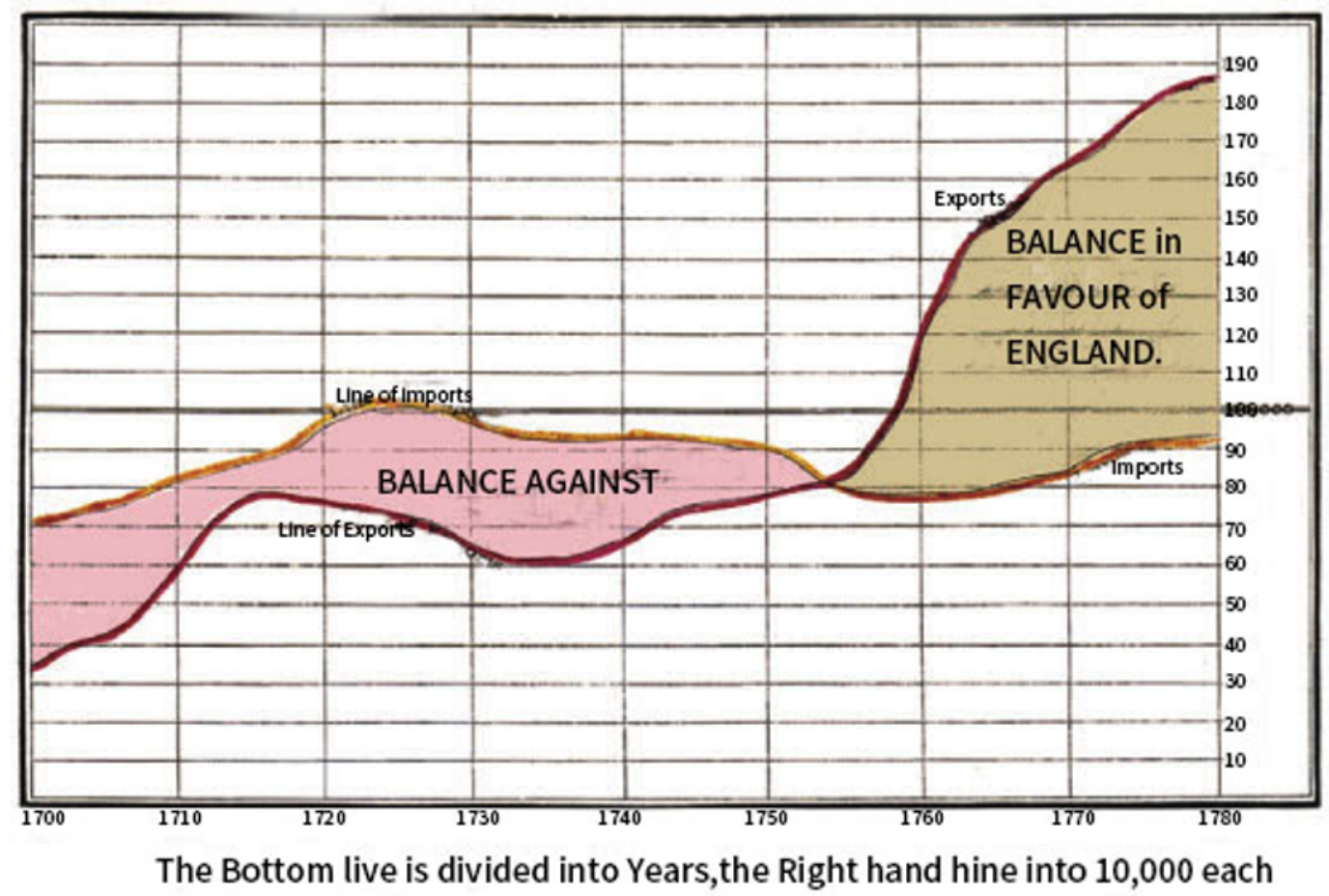

Figure 1. A map of Britain's imports and exports to Denmark and Norway in the 18th century, drawn by William Playfair 


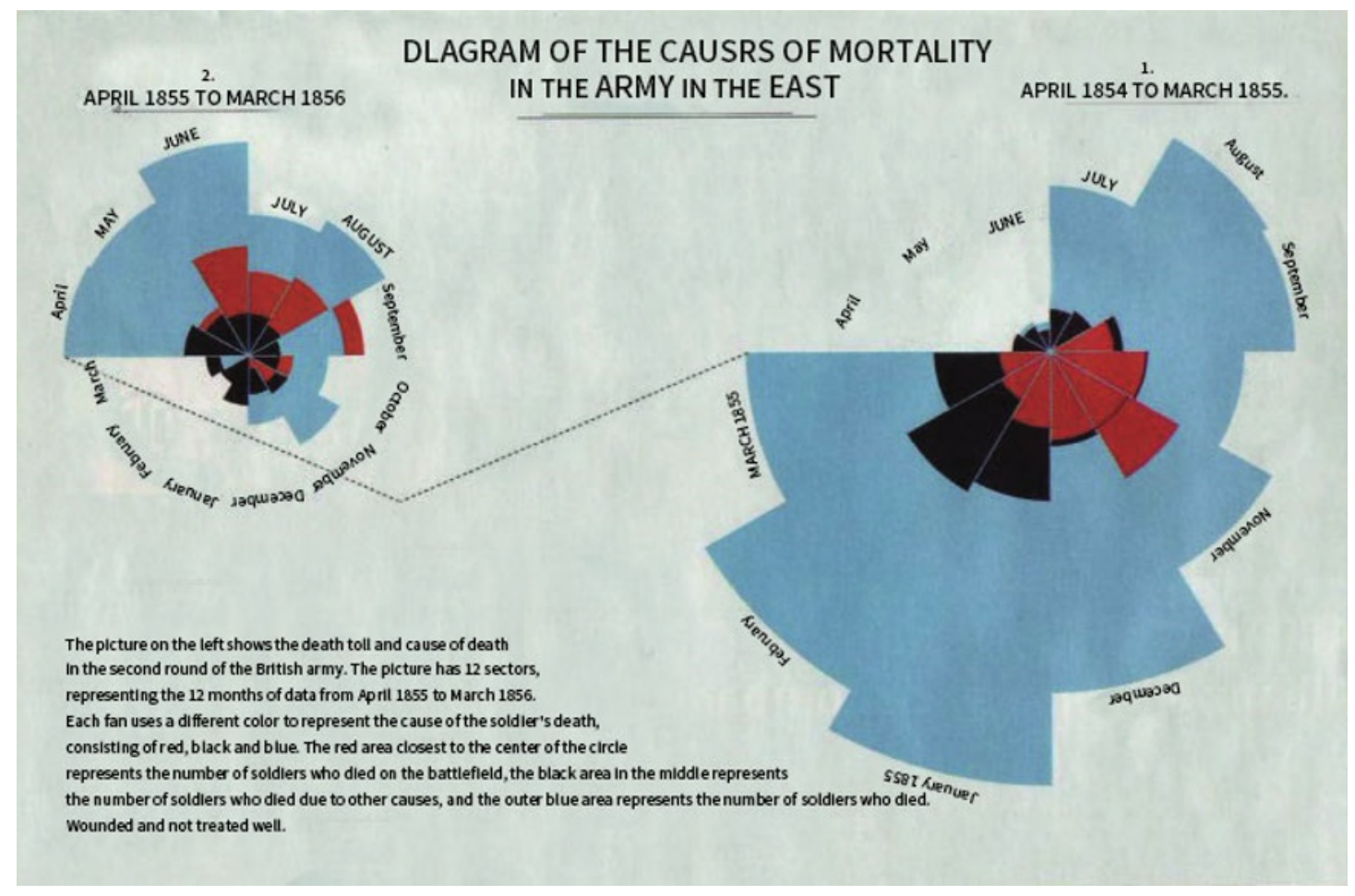

Figure 2. Nightingale rose diagram

\section{Case Analysis of Contemporary Data Visualization}

Entering the 20th century, especially after entering the information age, the visual presentation of information and content have also undergone earth-shaking changes, and the speed of update iterations is also increasing. Through this epidemic, we will find that infographics are the main manifestation of this epidemic data visualization design. Through the visual design, the massive and complex epidemic data information can be efficiently and clearly expressed to users. The human brain is easier to receive graphics. Information charts integrate and objectively describe information through graphic elements such as charts, illustrations, and charts, which greatly improves the readability and legibility of data information. The main presentation form of the epidemic data visualization design is an information chart, which efficiently and clearly transmits a large amount of complex epidemic data to users. Figure 3 shows an excerpt of the information chart in the epidemic data visualization design case, which shows the information charts used in the epidemic data visualization design case. Among them, the daily epidemic data, monthly epidemic data, and the distribution of infected people are presented in those simple charts, which are concise and easy to understand.

In order to understand the relationship between the various charts applied to the data and information, the different types of charts used in the visualization cases are classified and compared to understand how the data is presented in the various epidemic data visualization process to make it easier for users to understand, analysis.
The analysis of epidemic data visualization chart types is shown in Table 1, which lists the representative classic chart types used in ten epidemic data visualization cases, including histograms, graphs, maps, word clouds, barometers, square inch charts, etc. From the four perspectives of data information, usage, limitations and applications, longitudinally compare and analyze the regular characteristics of the chart in the information presentation process. It is not difficult to see that the curve graph shows the trend change of the fluctuation over time or the orderly category, which can reflect the change trend of the epidemic situation in various provinces, cities, the whole country, and overseas. The map uses the shade of the color to indicate the numerical value of the display area, which visually displays the spatial growth trend of the national and overseas epidemics, and can be used to analyze the spatial spread of the epidemic and the control of the source of infection. The word cloud displays text information, visually highlighting keywords that appear frequently, and can be used for visual analysis of social media. A mulberry chart is a specific type of flow chart used to represent data flow, which can be used to analyze the movement trajectory of the infected population during the epidemic, so as to effectively control the spread and deterioration of the epidemic. Scatter plots are mainly used to discover the relationship between variables and can be used for media attention analysis. Different types of icon applications provide a variety of forms and methods for the display of data information. Different types of charts have different applicable scenarios and various local limitations. Designers need to synthesize information and data, combine design purposes, and select appropriate charts. Type to present the data information you want to display. 


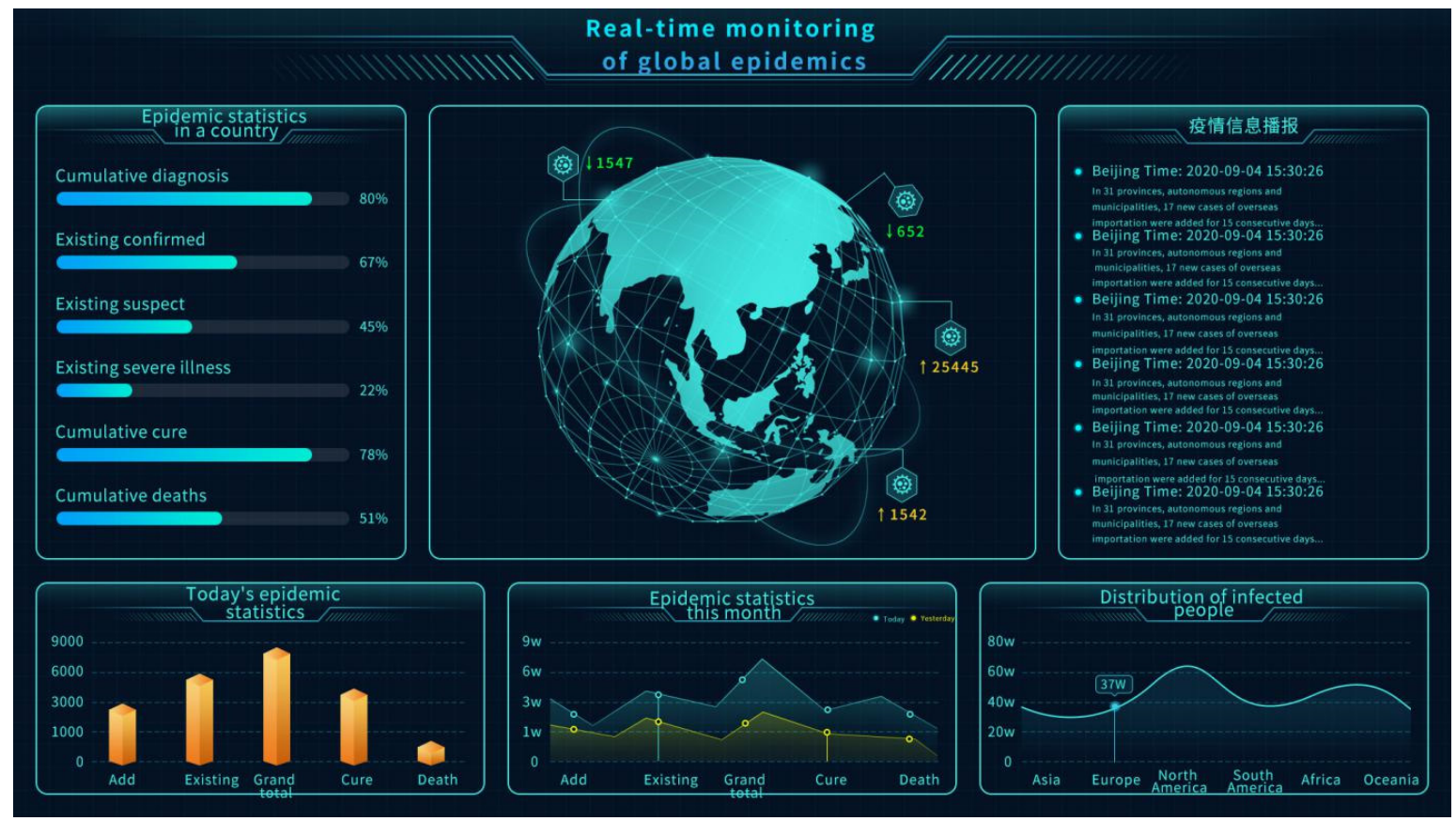

Figure 3. Global Epidemic Data Monitoring Chart

Table 1. Analysis of the characteristics of various types of charts

\begin{tabular}{|c|c|c|c|c|}
\hline Types of & Data information & Be applicable & Limitations & Application \\
\hline Histogram & $\begin{array}{l}\text { Show data changes in } \\
\text { multiple categories } \\
\text { and comparisons } \\
\text { between variables in } \\
\text { the same category }\end{array}$ & $\begin{array}{c}\text { For categorical } \\
\text { data }\end{array}$ & $\begin{array}{l}\text { Too many } \\
\text { classifications can } \\
\text { not show the } \\
\text { characteristics of } \\
\text { the data }\end{array}$ & Epidemics in key countries \\
\hline Graph & $\begin{array}{l}\text { Show the trend of } \\
\text { data fluctuations over } \\
\text { time or ordered } \\
\text { categories }\end{array}$ & $\begin{array}{l}\text { Ordered } \\
\text { categories, such } \\
\text { as time }\end{array}$ & $\begin{array}{l}\text { Unorganized } \\
\text { categories cannot } \\
\text { show data } \\
\text { characteristics }\end{array}$ & $\begin{array}{c}\text { City/Province/National/Overseas } \\
\text { Epidemic Trend; Hubei/Non-Hubei } \\
\text { Comparison; China/Overseas } \\
\text { Comparison; Cure Rate/Case } \\
\text { Fatality Rate/Severe Case Rate }\end{array}$ \\
\hline map & $\begin{array}{l}\text { Use the shade of the } \\
\text { color to show the } \\
\text { value of the area }\end{array}$ & $\begin{array}{l}\text { Display data } \\
\text { that is planar but } \\
\text { distributed }\end{array}$ & $\begin{array}{l}\text { Asymmetry in data } \\
\text { distribution and } \\
\text { geographic area } \\
\text { size } \\
\end{array}$ & $\begin{array}{l}\text { Hubei/national/global epidemic } \\
\text { situation; zero-growth map; entry } \\
\text { control measures of various } \\
\text { countries; }\end{array}$ \\
\hline Word cloud & $\begin{array}{c}\text { Display text } \\
\text { information and } \\
\text { visually highlight the } \\
\text { "keywords" that } \\
\text { appear frequently }\end{array}$ & $\begin{array}{c}\text { Extract } \\
\text { keywords from } \\
\text { large amounts of } \\
\text { text }\end{array}$ & $\begin{array}{l}\text { Not suitable for } \\
\text { text with too little } \\
\text { data or low data } \\
\text { discrimination }\end{array}$ & Social media visual analysis \\
\hline $\begin{array}{l}\text { Mulberry } \\
\text { Chart }\end{array}$ & $\begin{array}{l}\text { A specific type of } \\
\text { flow chart. The width } \\
\text { of the extended } \\
\text { branch in the figure } \\
\text { corresponds to the } \\
\text { size of the data flow. } \\
\text { The sum of the start } \\
\text { flow is always in } \\
\text { balance with the sum } \\
\text { of the end flow. }\end{array}$ & $\begin{array}{l}\text { Used to indicate } \\
\text { the flow of data }\end{array}$ & $\begin{array}{l}\text { Not applicable to } \\
\text { scenarios where } \\
\text { the start and end } \\
\text { traffic of an edge } \\
\text { are different }\end{array}$ & $\begin{array}{c}\text { Analysis of District (County) Data } \\
\text { Analysis of Action Tracks in } \\
\text { Chongqing }\end{array}$ \\
\hline Scatter plot & $\begin{array}{l}\text { Used to discover the } \\
\text { relationship between } \\
\text { variables }\end{array}$ & $\begin{array}{l}\text { There are a large } \\
\text { number of data } \\
\text { points, the } \\
\text { results are more } \\
\text { accurate, such as } \\
\text { regression } \\
\text { analysis } \\
\end{array}$ & $\begin{array}{l}\text { Small amount of } \\
\text { data will be more } \\
\text { confusing }\end{array}$ & Media attention analysis \\
\hline $\begin{array}{c}\text { Circle } \\
\text { diagram }\end{array}$ & $\begin{array}{l}\text { Organize through the } \\
\text { logical relationship of } \\
\text { cities, provinces, }\end{array}$ & $\begin{array}{l}\text { Emphasize the } \\
\text { comparison of } \\
\text { data under the }\end{array}$ & $\begin{array}{l}\text { You can only } \\
\text { roughly compare } \\
\text { the size }\end{array}$ & $\begin{array}{l}\text { The Flow of the Epidemic: Cases } \\
\text { and Places }\end{array}$ \\
\hline
\end{tabular}




\begin{tabular}{|c|c|c|c|c|}
\hline & $\begin{array}{c}\text { countries, and } \\
\text { international } \\
\text { administrative regions } \\
\text { from small to large, } \\
\text { using the structure of } \\
\text { a circle }\end{array}$ & $\begin{array}{l}\text { structural } \\
\text { organization } \\
\text { relationship }\end{array}$ & $\begin{array}{l}\text { relationship } \\
\text { between the } \\
\text { various data based } \\
\text { on the user's } \\
\text { feeling }\end{array}$ & \\
\hline Flow graph & $\begin{array}{l}\text { Show the trend of the } \\
\text { fluctuation of the data } \\
\text { over time, the width } \\
\text { reflects the quantity }\end{array}$ & $\begin{array}{l}\text { The data of } \\
\text { multiple } \\
\text { elements } \\
\text { fluctuates over } \\
\text { time, with } \\
\text { liquidity }\end{array}$ & $\begin{array}{l}\text { Approximately } \\
\text { reflect changes in } \\
\text { the overall data, } \\
\text { not conducive to } \\
\text { comparisons } \\
\text { between elements }\end{array}$ & $\begin{array}{c}\text { New daily cases of new coronavirus } \\
\text { pneumonia }\end{array}$ \\
\hline $\begin{array}{l}\text { Sunny and } \\
\text { rainy map }\end{array}$ & $\begin{array}{l}\text { Focus on incremental } \\
\text { data and present the } \\
\text { development trend of } \\
\text { the epidemic in a } \\
\text { macro view }\end{array}$ & $\begin{array}{l}\text { Help reveal the } \\
\text { turning point of } \\
\text { the epidemic }\end{array}$ & $\begin{array}{l}\text { Can only reflect } \\
\text { the increase, not } \\
\text { the total change }\end{array}$ & $\begin{array}{c}\text { The number of new diagnoses in the } \\
\text { country/world every day and its } \\
\text { changing trend }\end{array}$ \\
\hline $\begin{array}{l}\text { Square inch } \\
\text { map }\end{array}$ & $\begin{array}{l}\text { Focus on accumulated } \\
\text { data and show the } \\
\text { development trend of } \\
\text { the epidemic in a } \\
\text { macro view }\end{array}$ & $\begin{array}{l}\text { Macroscopically } \\
\text { show the } \\
\text { development of } \\
\text { the epidemic }\end{array}$ & $\begin{array}{l}\text { The general } \\
\text { response level, the } \\
\text { comparison } \\
\text { between the data is } \\
\text { not intuitive }\end{array}$ & Epidemic situation \\
\hline
\end{tabular}

\section{Conclusion}

Since the outbreak of the new crown pneumonia, we have been able to see real-time data released by various provinces, institutions and mainstream media almost every day. This information plays a vital role in improving residents' awareness of self-protection and doing a good job in epidemic prevention and control. I have to mention that in the Internet age, the speed of acquiring big information has been greatly improved, and the limitation of time and space has been broken. However, the moral information and the presentation of the secretaries we are exposed to are actually different. Text + number is one of the main forms in the release of the epidemic. It is the most common in mainstream media reports and on social platforms. Qi usually includes the cumulative number of confirmed cases, new suspected cases, new deaths, and new cured cases across the country. Important key data is shown in Figure 4. This type of data often appears in conjunction with news releases. It has the characteristics of timely and rapid news dissemination, which can satisfy the public's rapid grasp of the situation of the epidemic throughout the day. However, it is often limited by the text form, resulting in a strong sense of "stacking" of the data, difficult to highlight the key points, and the audience will have a certain pressure on the reading experience.

\section{References}

1. LI $\mathrm{T}(2020)$.Information visualization : design methods for the public to "see" the epidemic. Decoration Journal.J.02-38-45.

2. HUA R.(2020).Visualization design and dissemination of information on new crown pneumonia epidemic prevention in a new media environment. Sound screen world.J.

3. Xiang F.(2020).Research on Visual Art from the Perspective of visual Design. Literary Theory and

\section{Criticism.J.02:46-53.}

4. Wei J.(2018).Aesthetics, Cognition and Emotion in information Visualization Design. Popular literature.J.07:79-81.

5. Wei Z.(2013).A classic case of data information visualization. China Statistics.J.05:22-23 